\title{
Verification of the Fanger Model in Real Conditions
}

\author{
Natalia Krawczyk ${ }^{1}$, Andrej Kapjor ${ }^{2}$, and Łukasz J. Orman ${ }^{1, *}$ \\ ${ }^{1}$ Faculty of Environmental, Geomatic and Energy Engineering, Kielce University of Technology, \\ Poland \\ ${ }^{2}$ Faculty of Mechanical Engineering, University of Zilina, Slovakia
}

\begin{abstract}
This study presents the issue of thermal comfort based on the Fanger model. The research was conducted in 5 rooms in the autumnwinter period. The research consisted of measurement of thermal environment parameters, air temperature and flow rate, relative air humidity, globe temperature sensor and light intensity. During the research, the students filled in questionnaires concerning thermal sensation. This allowed them to express their assessment of thermal comfort (predicted mean vote PMV and predicted percentage of dissatisfied PPD), as well as their preferences concerning the prevailing room conditions. Differences between the actual average predicted rating index and the Fanger model were shown. It can be noted that Fanger's model does not reflect the results of the respondents.
\end{abstract}

\section{Introduction}

Thermal comfort is related to the feeling of temperature in the room. We are then neither too cold nor too warm. Nowadays, people spend about $90 \%$ of their lives indoors. Therefore, the issue of room thermal comfort is an important issue in air conditioning design. There are many techniques for determining thermal comfort. On their basis, international standards such as: PN EN ISO 7730 [1] together with ASHRAE 55 [2] and PN EN 15251 [3] were developed. According to the standard [1], thermal comfort can be expressed in terms of predicted mean vote (PMV) and predicted percentage of dissatisfied people (PPD). PMV and PPD were developed by Povl Ole Fanger. Using extensive literature and based on his own research, Fanger created the thermal comfort equation.

The human body, feeling the thermal comfort, is in a state of satisfaction with the thermal conditions of the environment that surrounds it. Such a person should be in the state of thermal equilibrium, i.e. between the amount of heat produced during metabolic processes and the amount of heat released to the environment [4]. When we are exposed to unfavorable conditions for a long time, our efficiency of performed activities decreases significantly. Because of this, we become less efficient. Also, staying in a room in adverse conditions, we cease to feel good, we begin to feel fatigue, headache, and we can even

${ }^{*}$ Corresponding author: orman@tu.kielce.pl 
get sick. That is why it is so important to control the air parameters in the room and try to maintain them at an appropriate level.

Everyone who uses the room is a source of external air pollution, mainly in the form of carbon dioxide. About 20 people are constantly in the classrooms and each of them produces $\mathrm{CO}_{2}$ in the process of breathing. Note that poor ventilation makes it harder to remove carbon dioxide concentration. It is necessary to ensure adequate ventilation of the room [5].

A lot of research was conducted on thermal comfort, among others in article [6] the author presented the essence of the concept of thermal comfort, using the Fanger model, which despite the passage of years is still used. Statistical heat balance of the human body and heat loss through sweating are discussed. A graph of thermal comfort and its changes for lightly dressed people at various levels of activity is also presented. Buratti [7] developed a model based on the Rholes approach, which enables PMV assessment by measuring relative humidity and temperature for various values of thermal insulation of clothing. Becker [8] showed the discrepancy between the value of PMV and the value of thermal sensations. PMV calculated using the Fanger model definitely underestimates these results. Moreover, the PPD curve of the percentage of dissatisfied exceeds the actual number of dissatisfied. Yu Yang et al. [9] described that PMV differs from thermal sensations. This may be due to the thermal habits of the inhabitants. When there are no rapid thermal changes, the body assumes that the conditions are neutral. When the Fanger model considers them unfavorable. Providing the thermal comfort conditions is a crucial issue [10-12].

\section{Description of the Fanger model}

The discussed PMV and PPD indices are associated with the Fanger comfort equation. The PMV indicator defines the average rating of a large group of people on a seven-grade scale [1]. Numeric values on this scale range from -3 to +3 . Positive values correspond to the warm side and negative values to the cold side. The PMV index is affected by such variables as: metabolic rate, air temperature and speed, clothing insulation, relative humidity. There are many factors that affect thermal comfort. Indoor movement and air parameters, physical activity performed by people, insulation of clothing and radiation from other devices and objects are of great importance.

To accurately analyze thermal phenomena in a room, it is necessary to calculate the average radiation temperature. Referring to a man dressed in a specific outfit and in a specific position at a given point inside a room, the average radiation temperature is called a homogeneous ambient temperature with black surfaces that could cause heat loss through radiation equal to heat loss in the environment [13]. The average radiation temperature will vary depending on the person's position and location in the room, because in fact it is different at different points in space. When we are exposed, for example, to solar radiation or radiation produced by some high-power radiant heaters, the average radiation temperature will depend on the ability to absorb radiation through the outer surface of the body covered with clothing [14]. The average radiation temperature was determined from formula (1) below [15]:

$$
\bar{T}_{r}=4 \sqrt{T_{g}^{4}+\frac{h_{c g}}{\varepsilon_{g} \sigma}}\left(T_{g}-T_{a}\right)
$$




\section{Research methodology}

The main purpose of this article is to estimate the thermal comfort by means of PMV. The research was conducted for 5 rooms with gravity ventilation. During the research, a microclimate meter was used to determine air parameters. The study consisted in measuring the parameters of the thermal environment, relative air humidity, air temperature and speed, black sphere temperature and light intensity. During this time, the subjects filled in a questionnaire concerning the characteristics of thermal sensations of the microclimate they were in. This allowed them to express their assessment of the thermal comfort as well as their preferences concerning the prevailing conditions in the room. Moreover, the respondents indicated the clothes they wore and the activities performed before the survey. On the basis of these data, Fanger's indices for thermal comfort were calculated (the predicted mean vote PMV and the predicted percentage of dissatisfied PPDs). Figure 1 shows a photo of the measuring station.

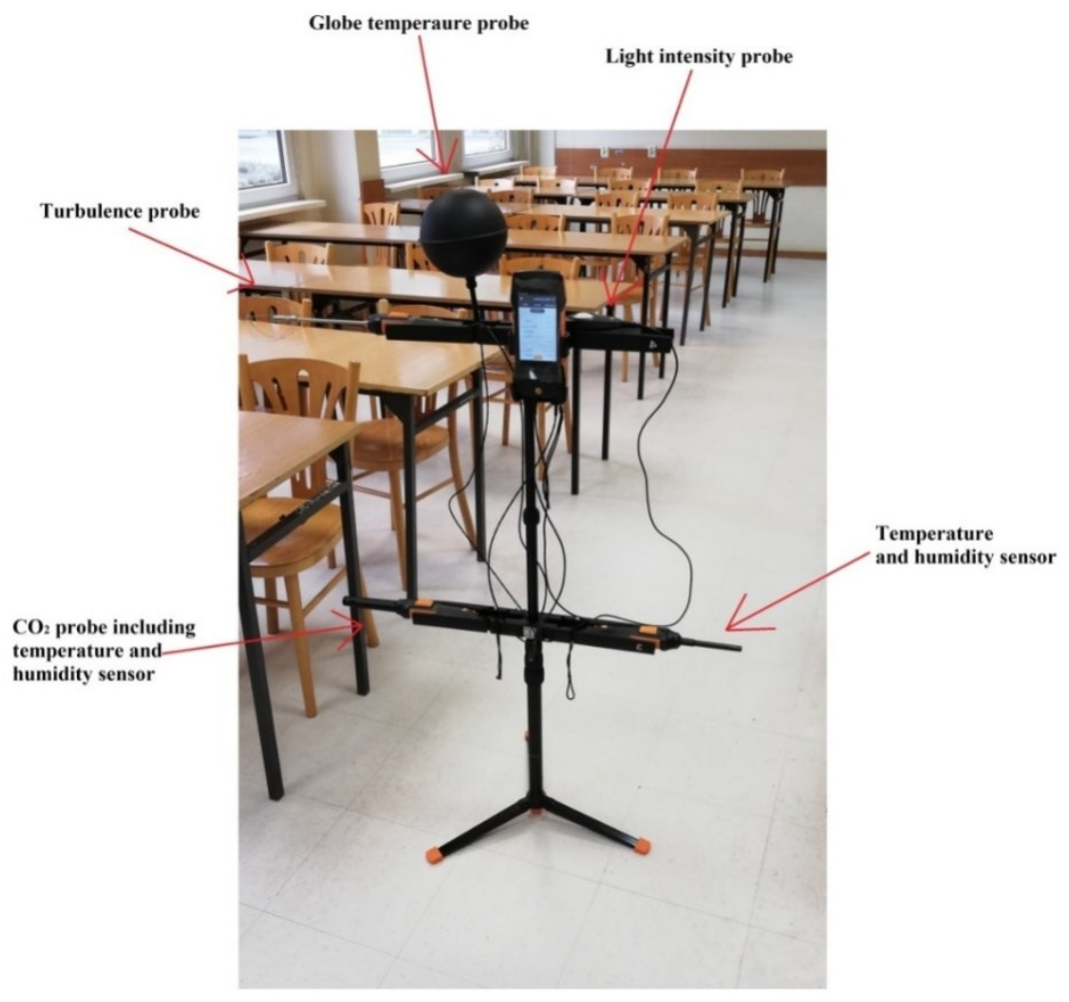

Fig. 1. Photograph of the measuring station.

The research was conducted with the use of measuring equipment in the autumn-winter period of 2019 and 71 people took part in it, out of which 20 questionnaires were rejected due to the fact that the answer "yes" was marked when asked about the current state of health and when asked about the activity performed in the last 30 minutes. The measured parameters included: air temperature, relative humidity, flow velocity, pressure, $\mathrm{CO}_{2}$ concentration and light intensity. Below the accuracy at which these parameters were measured is given [16]:

- indoor air temperature: $+/-0.3{ }^{\circ} \mathrm{C}$,

- relative humidity: $+/-2 \%$,

- flow velocity: $+/-0.3 \mathrm{~m} / \mathrm{s}$, 
- absolute pressure: $+/-3 \mathrm{hPa}$,

- concentration $\mathrm{CO}_{2}:+/-50 \mathrm{ppm}$.

The measurements were carried out after the steady state conditions were reached, because at first the meter needs to adjust to the conditions in the considered room. Figure 2 presents example changes of air and globe temperatures as well as carbon dioxide concentration.

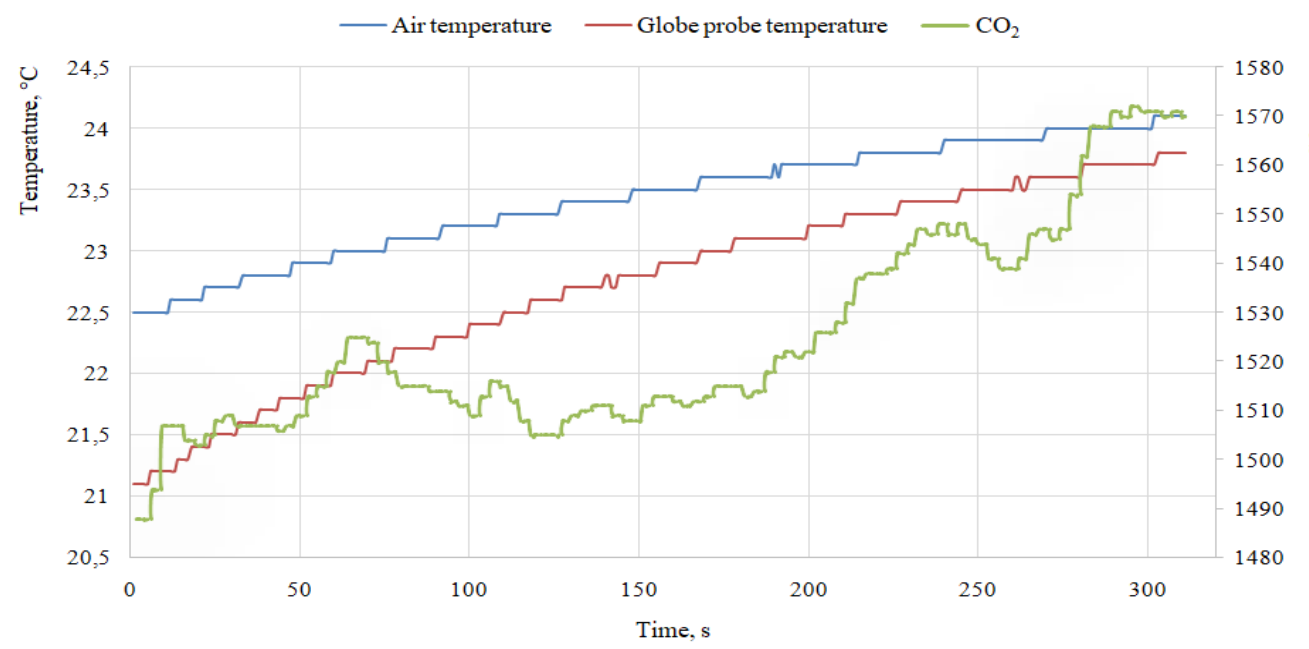

Fig. 2. Graph of temperatures and carbon dioxide changes over time.

From the graph it can be concluded that the air temperature and the temperature of the globe probe have a constant upward trend over time, while carbon dioxide is varied, it has different fluctuations. As the air temperature increases, and hence the globe probe, the carbon dioxide content increases over time. The increase in carbon dioxide is not even. At higher air temperatures, a person loses the impression of thermal comfort, and his body demands a greater demand for oxygen.

The thermal comfort parameters PMV and PPD have been calculated on the basis of the measurements, using formulas $(2,3)$. The PMV index is presented below according to [1]:

$$
\begin{gathered}
P M V=[0.303 \cdot \exp \cdot(-0.036 \cdot M)+0.028] \cdot\left\{(M-W)-3.05 \cdot 10^{-3} \cdot[5733-6,99 .\right. \\
\left.(M-W)-p_{a}\right]-0.42 \cdot[(M-W)-58.15]-1.7 \cdot 10^{-5} \cdot M \cdot\left(5867-p_{a}\right)-0.0014 \cdot M
\end{gathered}
$$

where: $M$ - metabolic rate $\left[\mathrm{W} / \mathrm{m}^{2}\right], W$ - effective mechanical power $\left[\mathrm{W} / \mathrm{m}^{2}\right], I_{c l}$ - thermal insulation of clothing $\left[\mathrm{m}^{2} \mathrm{~K} / \mathrm{W}\right], t_{a}$ - air temperature $\left[{ }^{\circ} \mathrm{C}\right], \bar{t}_{r}$ - average radiation temperature $\left[{ }^{\circ} \mathrm{C}\right], p_{a}$ - partial pressure of water vapour $[\mathrm{Pa}], t_{c l}$ - surface temperature of clothing $\left[{ }^{\circ} \mathrm{C}\right]$.

1 metabolic unit $=1$ meter $=58.2 \mathrm{~W} / \mathrm{m}^{2}$,

1 unit of thermal insulation of clothing $=1 \mathrm{clo}=0.155 \mathrm{~m}^{2 \circ} \mathrm{C} / \mathrm{W}$.

The PMV indicator is used to check whether a given thermal environment meets the comfort conditions and to determine different levels of acceptability.

The PPD indicator indicates the number of people who feel the environment is too cold or warm. By determining the PMV value, you can calculate the PPD from the following equation (3) according to [1]:

$$
P P D=100-95 \cdot \exp \cdot\left(-0.03353 \cdot P M V^{4}-0.2179 \cdot P M V^{2}\right)
$$


The factor causing discomfort is the cooling or heating of the user's body. Favorable factors are draughts, temperature differences between ankles and head or floor temperature.

51 respondents were taken into account for the analysis. For each object the parameters indicated by the meters were read. During the research, the respondents marked the answer which outfit they were wearing. On this basis, the type of clothing was averaged and the average level of insulation of the set was determined, adding the thermal resistance of the office chair of 0.1 clo. The respondents also marked the type of physical activity they had performed during the last 30 minutes. If they marked the answer "intensive physical effort (e.g. carrying heavy objects, aerobics, fast running, fast cycling)", the survey was rejected because there was a probability of heat sensation disruption. At the end of the questionnaire a metric was placed in which the person surveyed indicated their gender, age, height and weight. In most cases, young people aged 19 to 23 years predominated.

\section{Test results and their discussion}

After the temperature stabilized, the test results were read. Then, using the programme, the PMV and PPD indicators were determined on the website [17]. The key element was the question concerning the current heat sensations on a seven-stage scale from -3 (too cold) to +3 (too hot). After obtaining the average values for each room, the results of the drapes were compared with Fanger's model for PMV and PPD indicators. Figure 3 shows the results of testing the PMV coefficient for five rooms.

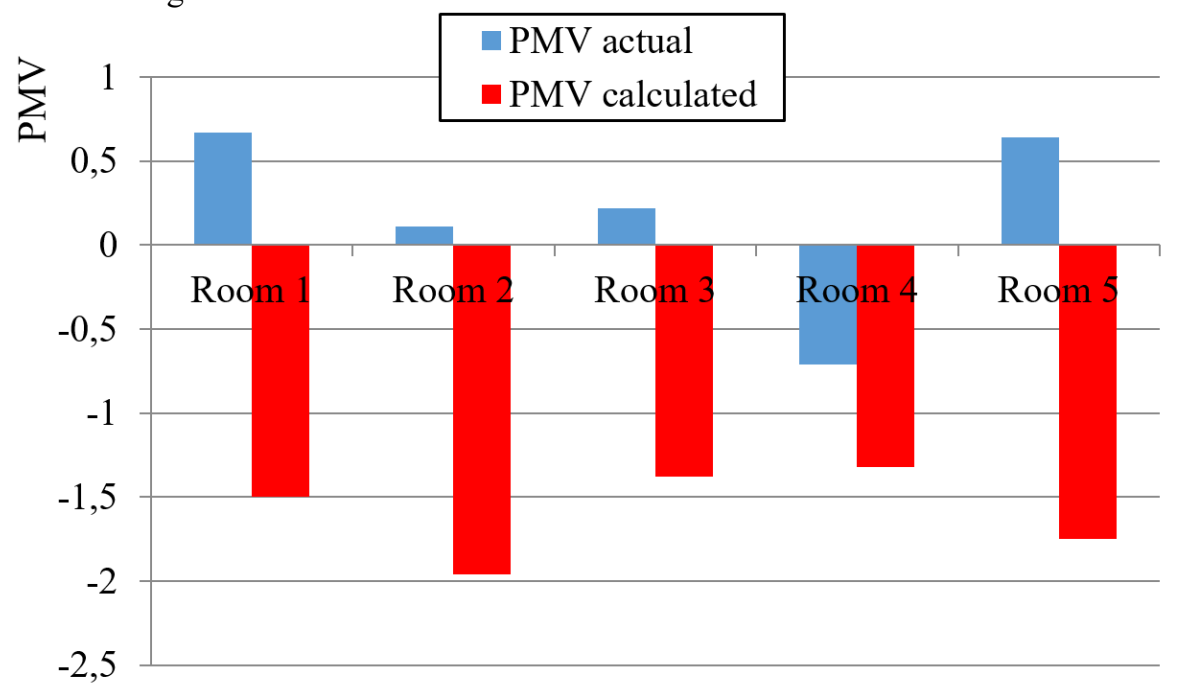

Fig. 3. Comparison of actual survey results and calculations according to the Fanger model for PMV.

It is clear that there is a significant discrepancy between the results of calculations according to the Fanger model and the results obtained in the course of research. These differences are more common and concern not only the results of the authors' own research. Figure 4 shows the relationship between the results of PMV calculations and data obtained from surveys - own [18] and taken from literature [19, 20].

The analysis of Figure 4 confirms that the Fanger model does not correctly map the actual thermal feelings of room users in various facilities. According to the graph above, it can be seen that the predicted mean vote PMV values deviate from the Fanger model. The figure shows the discrepancy between the standard PMV and the actual feelings of the 
respondents. These differences may be the result of the respondents adopting the conditions in which they stay for a long time to comfortable.

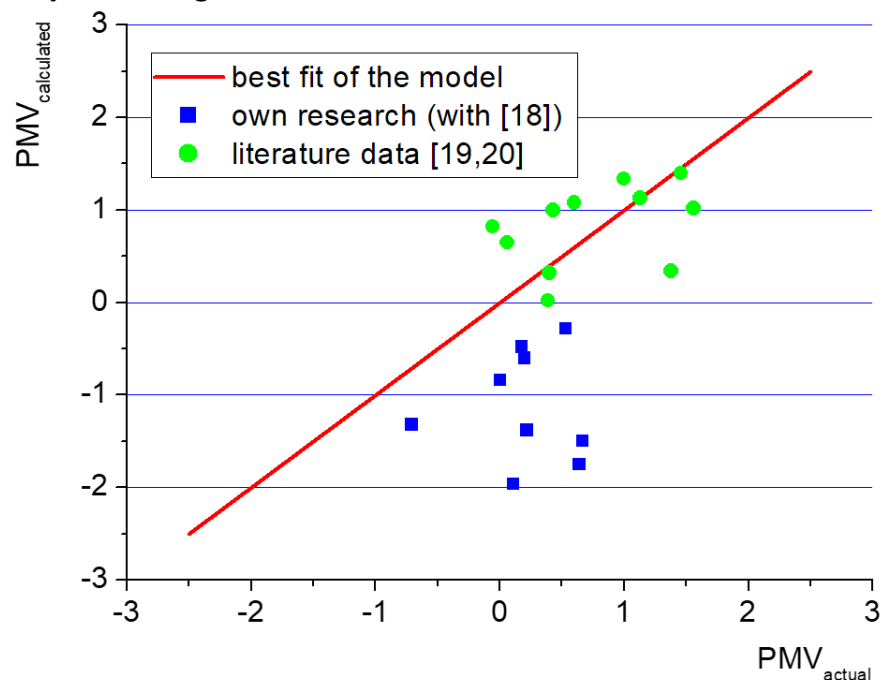

Fig. 4. Diagram of the perfect match between the Fanger model and actual PMV (from the questionnaires).

PPD is another important indicator when assessing thermal comfort. In this case, also the results obtained by calculations according to the model and from surveys for 5 rooms differ from each other (Figure 5).

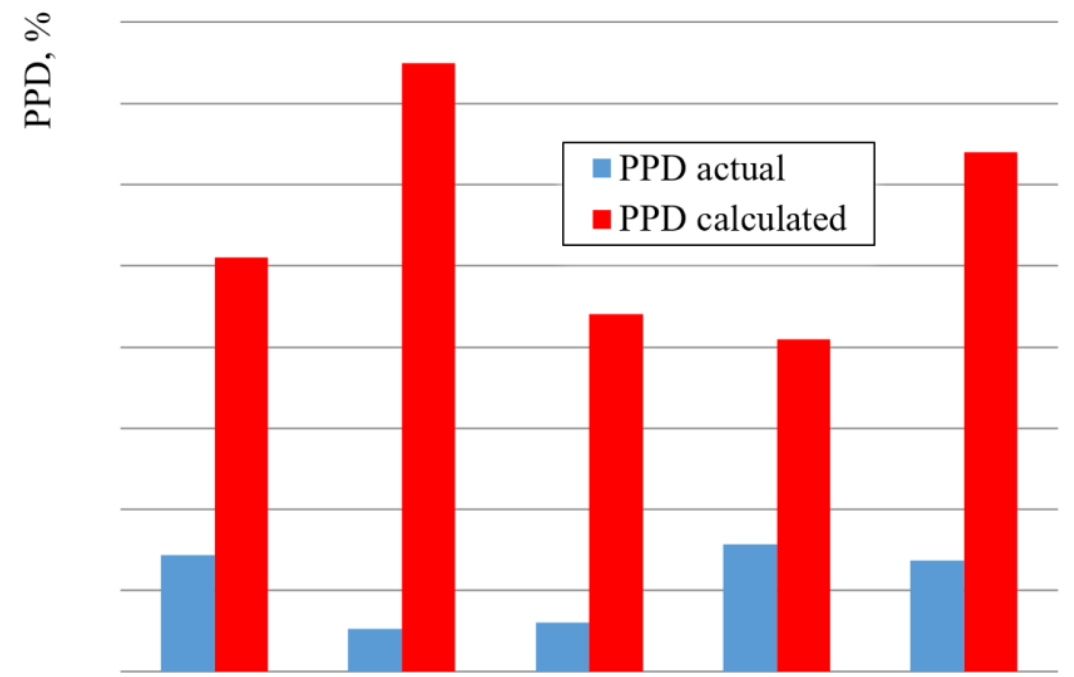

Fig. 5. Comparison of actual results and calculations according to the Fanger model.

The above figure shows the actual and Fanger model PPDs expressed in [\%]. It can be seen that the PPD values of the anticipated percentage of dissatisfaction according to the Fanger model do not coincide with the results obtained under real conditions. 


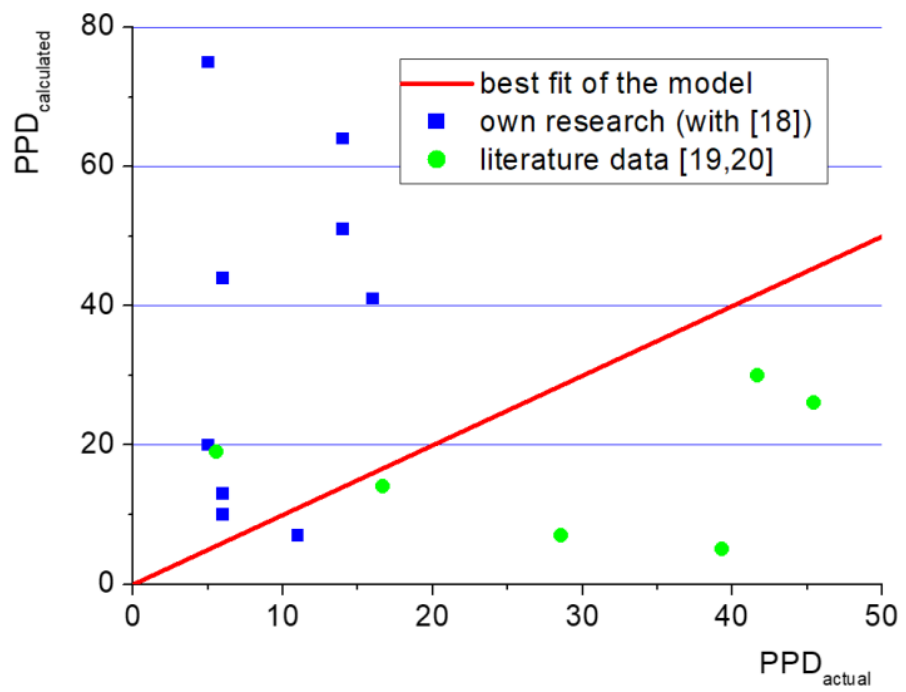

Fig. 6. Diagram of the perfect match between the Fanger model and actual PPD (from the questionnaires).

In all cases the discrepancies are significant. In this case, the analysis of own and literature data confirms earlier observations about the inaccuracy of the Fanger model (Figure 6).

\section{Summary and conclusions}

Based on the author's own research and analysis of the literature, it can be stated that there are significant discrepancies between the actual thermal comforts of people and the Fanger model. Therefore, the best solution will be to modify this model. The differences between the Fanger model and the actual feelings of the respondents can be considered a thermal adaptation caused by a long stay in a specific area. The absorption of given climatic conditions is highly dependent on psychological and physiological aspects. A person staying in unchanging conditions gets used to them. The thermal sensitivity of the skin is neutralized, and the examined person feels thermal comfort despite the often adverse conditions. A proposal for further research would be to compare two groups under the same climatic conditions. Confronting these groups could help indicate the answer to the thesis.

\section{References}

1. PN-EN ISO 7730: 2006 Ergonomics of the thermal environment - Analytical determination and interpretation of thermal comfort Rusing calculation of the PMV and PPD indices and local thermal Comfort criteria

2. ASHRAE STANDARD 55 - 2004: Thermal Environmental Conditions for Human Occuoancy

3. PN-EN 15251: 2006 Indoor environment al input parameters for design and assessment of energy performance of bildings ad dressing indor air quality, thermal environment, lighting and acoustics

4. L. Śliwowski: Fizyka budowli. Eds: P. Klemm. Tom II, Arkady, Warszawa (2005, 2006) 
5. Website: https://www.chlodnictwoiklimatyzacja.pl/artykuly/178-wydanie-72011-/192 5 - warunki-rodowiska- w-obiektach-edukacyjnych.html (access 29.01.2020)

6. I. Bartal, Hc. L. Banhidi, L. Garbai, Energy and Buildings, Department of Building Service Engineering and Process Engineering, Budapest University of Technology and Economics, Muegyetem" rkp. 3, Hungary (2012)

7. C. Buratti, D. Palladino, P. Ricciardi, Applied Energy 180, 859-866 (2016)

8. R. Becker, M. Paciuk: Thermal comfort in residential buildings - Failure to predict by Standard model, Building and Environment 44, 948-960 (2009)

9. Y. Yang, B. Li, H. Liu, M. Tan, R. Yao, Applied Thermal Engineering 76, 283-291 (2015)

10. P. Vician, P. Ďurčanský, J. Jandačka, MATEC Web of Conferences 168, 07015 (2018)

11. Z. Kolková, P. Hrabovský, J. Matušov, R. Nosek, MATEC Web of Conferences 168, 04002 (2018)

12. M. Malcho, R. Lenhard, K. Kaduchová, D. Hečko, S. Gavlas, AIP Conference Proceedings 2118, 030029 (2019)

13. P.O. Fanger: Komfort cieplny, Arkady (1974)

14. Website: https://www.termocert.com.pl/ocena-komfortu-cieplnego/temperatura-pomi eszczen.html (access 29.01.2020)

15. PN-ISO 7726: 2001 Ergonomia środowiska termicznego. Przyrządy do pomiaru wielkości fizycznych

16. Website: https://static-int.testo.com/media/1f/c3/9d43e2c6c57f/testo-400-InstructionManual.pdf (access 05.02.2020)

17. Website: http://comfort.cbe.berkeley.edu/ (access 29.01.2020)

18. N. Krawczyk, Z. Piasta, Structure and Environment, No.4. 281-286 (2019)

19. G. Majewski, M. Telejko, Ł. J. Orman, E3S Web of Conferences 17, EKO-DOK (2015)

20. G. Majewski, M. Telejko, Ł. J. Orman, Civil and Environmental Engineering, Vol.13, 72-76 (2017) 